\title{
Effects of Nerve Growth Factor and Nitric Oxide Synthase Inhibitors on Amyloid Precursor Protein mRNA Levels and Protein Stability
}

\author{
Janet C. MacKinnon, Patricia Huether and Bettina E. Kalisch*
}

Department of Biomedical Sciences, University of Guelph, Guelph, Ontario, N1G 2W1, Canada

\begin{abstract}
We determined previously that nitric oxide (NO) modulates the nerve growth factor (NGF)-mediated increases in amyloid precursor protein (APP) levels in PC12 cells. To elucidate potential mechanisms, the effects of NGF and NO synthase (NOS) inhibitors on APP mRNA levels and protein stability were evaluated. Surprisingly, treatment of PC12 cells with NGF resulted in decreased levels of APP695 and APP751/770 mRNA. Therefore, the effect of NGF on APP protein stability was examined using the translation inhibitor, cycloheximide. Under these conditions, NGF did not alter the rate of APP degradation, suggesting that NGF may be enhancing the translation rate of APP. Since NOS inhibitors attenuate the NGF-mediated increase in APP levels, their effect on APP mRNA levels and protein stability was also assessed. S-methylisothiourea (S-MIU), selective for inducible NOS, decreased both APP695 and APP751/770 mRNA levels while the non-selective NOS inhibitor, $\mathrm{N}^{\omega}$-nitro-L-arginine methylester (L-NAME) had no effect. In both control and NGF-treated PC12 cells, S-MIU increased the half-life of APP, with the greatest effect observed with the APP695 isoform. Based on these data we propose that in PC12 cells, NGF increases APP levels through enhanced translation rate and that NO, which modulates the NGF-induced increase in APP protein, also regulates APP mRNA levels and could play a role in APP processing.
\end{abstract}

Keywords: Amyloid precursor protein, mRNA, nerve growth factor, nitric oxide, PC12 cells, protein stability.

\section{INTRODUCTION}

Currently, elevated levels of amyloid $\beta$-protein $(A \beta)$ are most often implicated in the progression of Alzheimer's disease (AD; reviewed in [1]). $A \beta$ is produced during the normal cleavage of the glycoprotein amyloid precursor protein (APP), which is expressed in the membrane of neurons and glial cells [2]. Alternative splicing of the APP gene results in the generation of several isoforms, ranging in size from 365 to 770 amino acids, with APP695 being the most abundantly expressed isoform in the brain [3-5]. While many studies have focused on APP metabolism and the production of $A \beta$, the mechanisms involved in regulating APP isoform expression have not been elucidated.

Nerve growth factor (NGF), a neurotrophin reported to benefit $\mathrm{AD}$ patients [6], has also been found to modulate the levels and post-translational processing of APP. Several studies, using PC12 cells or primary neurons have reported that NGF increases APP mRNA and protein levels [7 - 10]. In PC12 cells, this is primarily the result of an up-regulation of the APP695 isoform [7, 10]. The levels of all three isoforms of nitric oxide synthase (NOS) are also increased following treatment with NGF $[11,12]$ and we found that NOS inhibitors attenuate the increase in APP protein levels caused by NGF [7]. Interestingly, we also found that this inhibition of NOS only partially attenuated the increase in APP promoter activation mediated by NGF [7] suggesting that NGFsignal transduction pathways and NO may be influencing

*Address correspondence to this author at the Department of Biomedical Science, University of Guelph, Guelph, Ontario, N1G 2W1, Canada;

Tel: 519-824-4120; Fax: 519-767-1450; E-mail: bkalisch@uoguelph.ca the rate of APP mRNA or protein synthesis or degradation in addition to altering gene transcription. Therefore, in the present study we investigated the effects of NGF and NOS inhibitors, alone and in combination, on APP mRNA levels and protein stability in PC12 cells. We determined previously that the non-selective inhibitor, $\mathrm{N}^{\omega}$-nitro-L-arginine methylester (L-NAME) and s-methylisothiourea (S-MIU), selective for the inducible NOS isoform [13], inhibited NOS activity in PC12 cells [11] and modulated NGF-induced APP expression [7]. Therefore these inhibitors were used to examine the role of NO on steady-state APP mRNA and protein levels. APP protein stability was assessed in PC12 cells exposed to NGF and/or NOS inhibitors followed by treatment with the translation inhibitor cycloheximide.

\section{MATERIALS AND METHODS}

\section{Materials}

Dulbecco's modified Eagle medium (DMEM), horse serum, gentamycin, Trizol and reverse transcription reagents were supplied by Invitrogen (Carlsbad, CA) and fetal bovine serum was purchased from HyClone Laboratories (Logan, UT). Harlan Bioproducts for Science (Indianapolis IN) was the supplier for NGF and Sigma Aldrich (St. Louis, MO) the source for L-NAME, S-MIU, actinomycin D, cycloheximide and the mouse monoclonal $\alpha$-tubulin antibody. The complete mini tablets were obtained from Roche Diagnostics (Laval, QC), the protein standards and sodium dodecyl sulfate (SDS) sample buffer were purchased from New England Biolabs (Ipswich, MA) and the SYBR green polymerase chain reaction reagents were from Qiagen (Mississauga, ON). Mouse monoclonal anti-APP was purchased from Chemicon Inter- 
national (Temecula, CA) and Amersham/GE Health Care (Piscataway, N.J.) supplied the Hybond blotting membrane, sheep anti-mouse IgG, Rediprime ${ }^{\circledR}$ random primer labelling system and the enhanced chemiluminescence (ECL) kit. All other chemicals were purchased either from Fisher Scientific (Ottawa, ON) or DiaMed Laboratories (Mississauga, ON) and were electrophoresis or molecular grade.

\section{PC12 Cell Culture}

PC12 cells were maintained, plated and treated as described previously [7, 11]. Media consisted of DMEM supplemented with $5 \%$ fetal bovine serum, $5 \%$ horse serum and $50 \mu \mathrm{g} / \mathrm{mL}$ gentamycin and cells were plated onto Corning ${ }^{\circledR}$ CellBind ${ }^{\circledR}$ coated dishes at a density of 2.0 million cells per $100 \mathrm{~mm}$ dish for RNA analysis and at a density of 1.0 million cells per $60 \mathrm{~mm}$ dish for protein analysis, $24 \mathrm{~h}$ prior to experiments.

\section{NGF and Inhibitor Treatments}

To determine a temporal profile for the effects of NGF on APP levels, samples from untreated PC12 cells or cells treated with $50 \mathrm{ng} / \mathrm{mL}$ NGF were collected at 12 or 24 hour intervals for a maximum of $96 \mathrm{~h}$. The cell culture media and NGF treatment was replaced every 48 hours. The role of NO on APP mRNA levels or protein stability was examined in PC12 cells treated with $20 \mathrm{mM}$ L-NAME or 0.5 to $2.0 \mathrm{mM}$ S-MIU alone or $1 \mathrm{~h}$ before treatment with NGF $[7,11]$. The effect of NGF on APP mRNA half-life was assessed in PC12 cells treated for $24 \mathrm{~h}$ with NGF followed by treatment with 1 $\mu \mathrm{g} / \mathrm{mL}$ actinomycin $\mathrm{D}$ for $1,2,4$ or $8 \mathrm{~h}$. The effect of NGF on APP protein translation was assessed in PC12 cells treated for $72 \mathrm{~h}$ with NGF or NOS inhibitors, alone or in combination, followed by treatment with $10 \mu \mathrm{g} / \mathrm{mL}$ cycloheximide for $0.25,0.5,1$ or $2 \mathrm{~h}$. For protein studies, media and treatments were replaced at the $48 \mathrm{~h}$ time-point, as described above.

\section{Immunoblot Analysis}

PC12 cell samples were obtained and analyzed as described previously [7]. Briefly, cells were lysed in $250 \mu \mathrm{L}$ of radioimmunoprecipitation assay (RIPA) buffer, rocked on ice for $15 \mathrm{~min}$, sonicated and centrifuged for $15 \mathrm{~min}$ at 17 530 g. Supernatant protein content was determined by the method of Bradford [14] and $35 \mu \mathrm{g}$ of cell lysate was boiled in SDS sample buffer. Proteins were separated by $10 \%$ SDS/polyacrylamide gel electrophoresis and transferred onto Hybond-C nitrocellulose membranes using a Trans-blot semidry transfer unit (Bio-Rad Laboratories, Mississauga, ON). Membranes were blocked for $1 \mathrm{~h}$ in $5 \%$ non-fat milk in TRIS-buffered saline (TBS) containing $0.1 \%$ Tween-20 (TBS-T). Membranes were incubated over night in 1:50,000 anti- $\alpha$-tubulin or 1:500 anti-APP in 5\% non-fat milk in TBST. Proteins were detected following a $1 \mathrm{~h}$ exposure to1:2000 horseradish peroxidase conjugated sheep anti-mouse IgG in $5 \%$ non-fat milk in TBS-T, ECL and subsequent scanning of the membranes with the STORM 860 (Molecular Dynamics, subsidiary of Amersham). Relative protein levels were and quantified densitometrically using Imagequant software (Molecular Dynamics).

\section{Quantitative RT- PCR}

Total RNA was isolated from PC12 cells using Trizol. Extracted RNA ( $5 \mu \mathrm{g}$ ) was reverse transcribed with Superscript II, using oligo-dt as the primer, for $75 \mathrm{~min}$ at $43^{\circ} \mathrm{C}$ and the cDNA generated was used for real-time PCR. All PCR reactions were performed in a LightCycler (Roche Diagnostics) using SYBRgreen PCR reagents in a final volume of 10 $\mu \mathrm{L}$. Each cycle began with an initial activation phase at $95^{\circ} \mathrm{C}$ for $15 \mathrm{~min}$ followed by 45 cycles of $15 \mathrm{~s}$ at $95^{\circ} \mathrm{C}, 20 \mathrm{~s}$ at $55^{\circ} \mathrm{C}$ and $15 \mathrm{~s}$ at $72^{\circ} \mathrm{C}$. The primers used to amplify APP and the house keeping gene beta- 2 microglobulin were: APP forward: 5' cgt ttg tga gcc cca tct tc 3', APP reverse: 5' ttc ctc ctc ttc ggc tac ttc 3', beta-2 microglobulin forward: 5' tga ccg tga tct ttc tgg gtg 3' and beta-2 microglobulin reverse: 5 ' atc tga ggt ggg tgg aac ctg 3 '.

\section{Northern Blot Analysis}

Total RNA was isolated from PC12 cells as described above. For each sample, $20 \mu \mathrm{g}$ of RNA was subjected to electrophoresis in $0.8 \%$ formaldehyde/agarose gels and transferred to nylon membranes (Hybond N) using a semi-dry transfer apparatus (Bio-Rad Laboratories). Membranes were UV-cross-linked and prehybridized at $42{ }^{\circ} \mathrm{C}$ for $1 \mathrm{~h}$ in $6 \times$ SSPE (saline/sodium phosphate/EDTA), $0.5 \%$ SDS, $5 \times$ Denhardts' reagent, $20 \mu \mathrm{g} / \mathrm{mL}$ salmon sperm DNA, and $50 \%$ formamide. Probes were generated for rat APP695 and APP751/770 by PCR using the following primers: APP695 forward: 5' tga aaa gct tgt agt ccg agt tcc cac gac 3' , APP695 reverse: 5' tgt tac tag tct tcc tgt tcc aga gat tcc aac 3', APP751/770 forward: 5' act gaa gct ttc ttt tac ggc gga tgt g 3' and APP751/770 reverse: 5' aag aac tag tac ctc tct ttg gct ttc tgg 3' A cDNA probe for murine 7S RNA [15] was used to normalize RNA loading. The probes were radiolabelled using $50 \mu \mathrm{Ci}$ of $\left[\mathrm{cc}^{32} \mathrm{P}\right] \mathrm{dCTP}$ and the Rediprime ${ }^{\circledR}$ random primer labelling system and incubated with the membranes at $42^{\circ} \mathrm{C}$ for $18 \mathrm{~h}$ in a solution identical to the prehybridization solution. Membranes were washed twice (15 min each) in $2 \times \mathrm{SSC}, 1 \%$ SDS at $42^{\circ} \mathrm{C}$ and once (30 min) in $0.1 \times$ SSC, $0.1 \%$ SDS at 55 to $60^{\circ} \mathrm{C}$. For APP695 or APP751/770, the blots were left in phosphoimaging cassettes for $48 \mathrm{~h}$, while the $7 \mathrm{~s}$ blots were exposed for $30 \mathrm{~min}$. The phosphoimaging screens were then scanned on the STORM 860 (Molecular Dynamics) for visualization and the bands analyzed densitometrically using Imagequant software (Molecular Dynamics).

\section{Data Analysis and Statistics}

Real-time PCR analysis was carried out using RelQuant software (Roche Diagnostics) and APP levels were quantified relative to beta-2 microglobulin levels in the same sample. For the analysis of both western and northern blots, bands for APP, $\alpha$-tubulin (for protein) or 7s (for RNA) were analyzed densitometrically and levels expressed as a percentage of the total amount of each protein or mRNA level present on the entire blot [as in 7]. APP protein levels were then expressed relative to $\alpha$-tubulin and APP RNA normalized to $7 \mathrm{~s}$ levels within the same sample. At least 4 independent experiments were run for each data point and the data are presented as the mean \pm standard error of the mean (SEM). All data were assessed for normality and homogene- 
ity of variance and statistical analysis was carried out using a one-way analysis of variance (ANOVA). To determine significant differences between treatment groups, ANOVA was followed by either the Dunnett or Tukey-Kramer multiple comparisons test. Mean values were considered different if $p<0.05$.

\section{RESULTS}

\section{Effect NGF on APP mRNA Levels}

To assess the temporal effects of NGF on APP mRNA, PC12 cells were treated with $50 \mathrm{ng} / \mathrm{mL}$ NGF and the samples collected at $24 \mathrm{~h}$ intervals for a maximum of $96 \mathrm{~h}$. Using primers that detected total APP mRNA (both APP695 and 751/770 isoforms), real-time PCR analysis revealed a

A

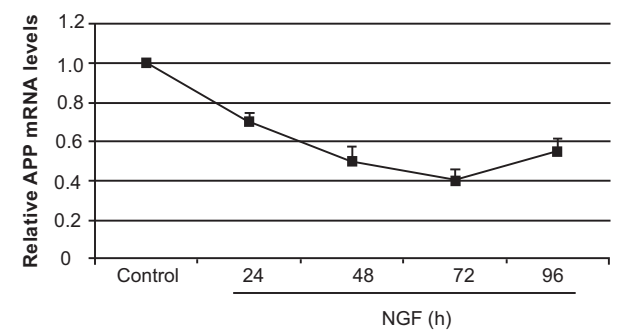

C

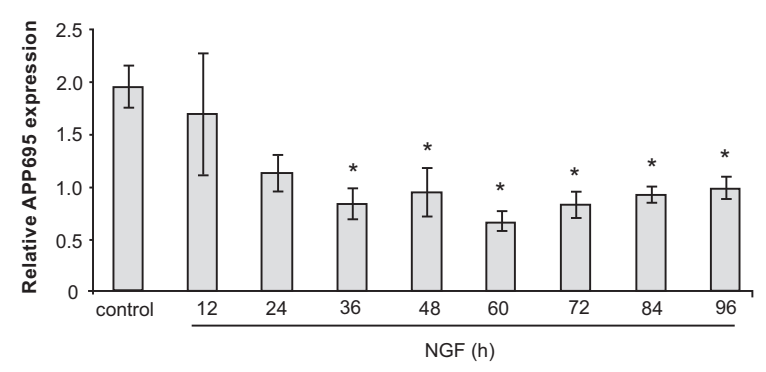

decrease in the steady-state levels of APP mRNA (Fig. 1A). To confirm these findings and to determine whether this NGF-mediated decrease was isoform selective, PC12 cells were treated with $50 \mathrm{ng} / \mathrm{mL}$ of NGF, RNA harvested at $12 \mathrm{~h}$ intervals for $96 \mathrm{~h}$ and mRNA levels evaluated using probes generated to detect APP695 and APP751/770 specifically by northern blot analysis (Fig. 1B). Again, densitometric analysis revealed that steady-state mRNA levels of APP were reduced following NGF treatment, with significant decreases in APP695 mRNA detected from 36 to $96 \mathrm{~h}$ (Fig.1C; * $\mathrm{p}<0.05$ ) and a significant decrease in APP751/770 detected between 24 and 96 h (Fig. 1D; *p < 0.05 ; *** $\mathrm{p}<0.001$ ) of NGF treatment. The effect of NGF on APP mRNA half-life was examined in samples obtained from cells cultured with or without NGF for $24 \mathrm{~h}$ and treated

B

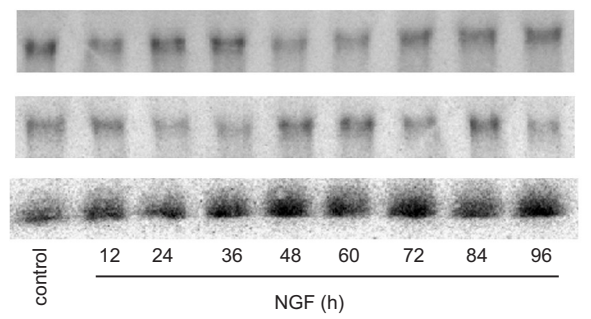

D

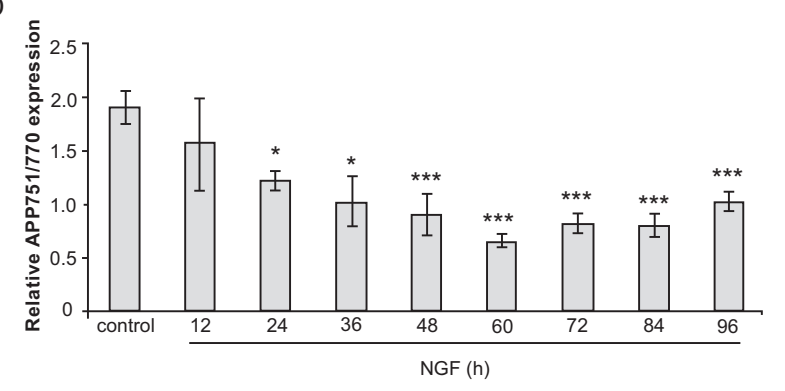

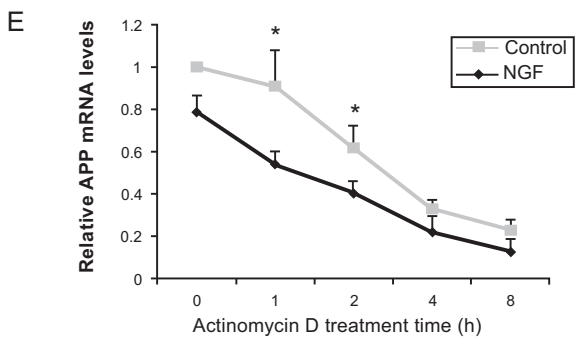

Fig. (1). Analysis of steady-state APP mRNA expression. (A) Real-time PCR analysis of total APP mRNA relative to beta-2 microglobulin levels following treatment with $50 \mathrm{ng} / \mathrm{mL}$ NGF. (B) Representative northern blots of APP695 (upper panel), APP751/770 (middle panel) and 7s (lower panel) expression in control (untreated) and NGF (50 ng/mL) treated PC12 cells. (C) Densitometric analysis of steady-state APP695 mRNA expression normalized to 7s. Treatment with NGF from 36 to 96 h resulted in a statistically significant (*p < 0.05$)$ decrease in APP695 mRNA expression. (D) Densitometric analysis of steady-state APP751/770 mRNA expression normalized to 7s. Treatment with NGF from 24 to 96 h resulted in a statistically significant $\left({ }^{*} \mathrm{p}<0.05 ; * * * \mathrm{p}<0.001\right)$ decrease in APP751/770 mRNA expression. (E) Real-time PCR analysis of total APP mRNA relative to beta-2 microglobulin levels in control and $24 \mathrm{~h}$ NGF exposed cells treated with actinomycin D for 1, 2, 4 or $8 \mathrm{~h}$. Significantly lower levels of relative APP mRNA were observed following treatment with NGF in the absence of actinomycin D and when treated with actinomycin D for 1 or $2 \mathrm{~h}\left({ }^{*} \mathrm{p}<0.05\right)$. Data are presented as the mean \pm SEM and represent 4 (E), 5 (A) or 6 (B, C and D) independent experiments. Statistical significance was determined by performing a one-way ANOVA followed by the Dunnett test to determine any significant differences between control and each time point. 
with actinomycin D for 1, 2, 4 and $8 \mathrm{~h}$. Since the effect of NGF was not isoform specific, APP mRNA levels were assessed using real-time PCR with primers that detected total APP (Fig. 1E). The level of APP mRNA was lower in cells treated with NGF relative to control in the absence of actinomycin $\mathrm{D}$ and following treatment with actinomycin D for 1 and $2 \mathrm{~h}\left({ }^{*} \mathrm{p}<0.05\right)$. Although the estimated APP mRNA half-life was shorter in NGF treated cells $(2.1 \mathrm{~h})$ compared to control $(2.8 \mathrm{~h})$ this difference was not statistically significant.

\section{Effect of Cycloheximide D on APP Protein Levels}

To examine whether NGF influences APP protein stability, cells were cultured in the presence or absence of NGF for $72 \mathrm{~h}$ and treated with cycloheximide from $15 \mathrm{~min}$ to $2 \mathrm{~h}$. Representative western blots depicting APP and $\alpha$ tubulin levels under these treatment conditions are presented in Fig. (2A). We determined previously that the highest

A

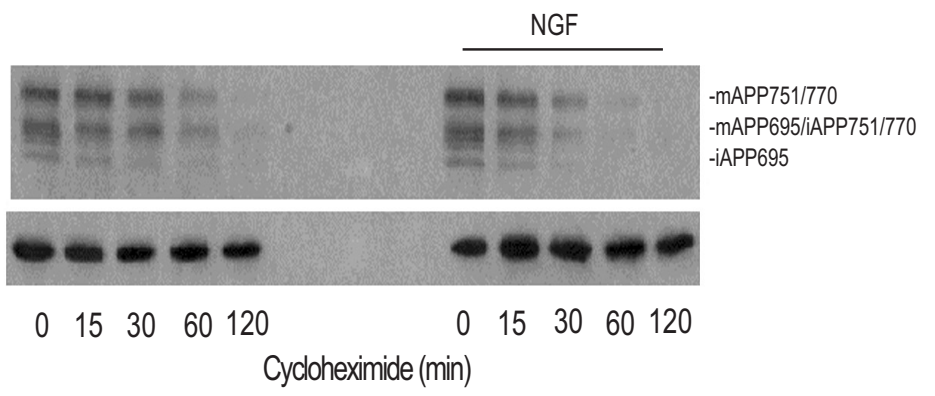

C

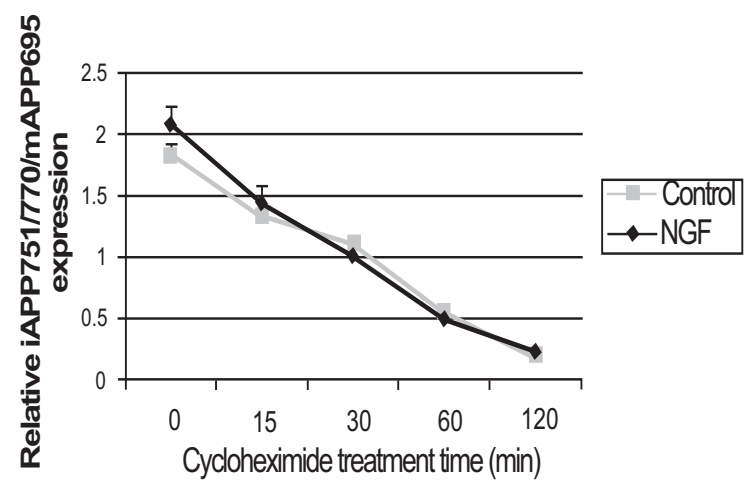

D protein band in the upper panel of Fig. (2A) shows mature APP751/770 and the immature APP695 isoform is depicted in the lowest band [7]. The middle band in this upper panel, which can sometimes be seen as 2 distinct bands, contains both immature APP751/770, and mature APP695. Relative expression of $\alpha$-tubulin levels from the same samples is shown in the bottom panel of Fig. (2A). Following densitometric analysis, protein levels of the highest molecular weight APP isoform (Fig. 2B) and the lower band (Fig. 2D) that contained the immature APP695 isoform were significantly higher than control $(* \mathrm{P}<0.05)$ prior to the addition of cycloheximide but no difference in the levels or rate of decay of APP was observed at any of the time points following treatment with cycloheximide. The levels of immature APP751/770 and mature APP695 (Fig. 2C) was not different following $72 \mathrm{~h}$ of NGF treatment in the presence or absence of cycloheximide at any of the time points examined.
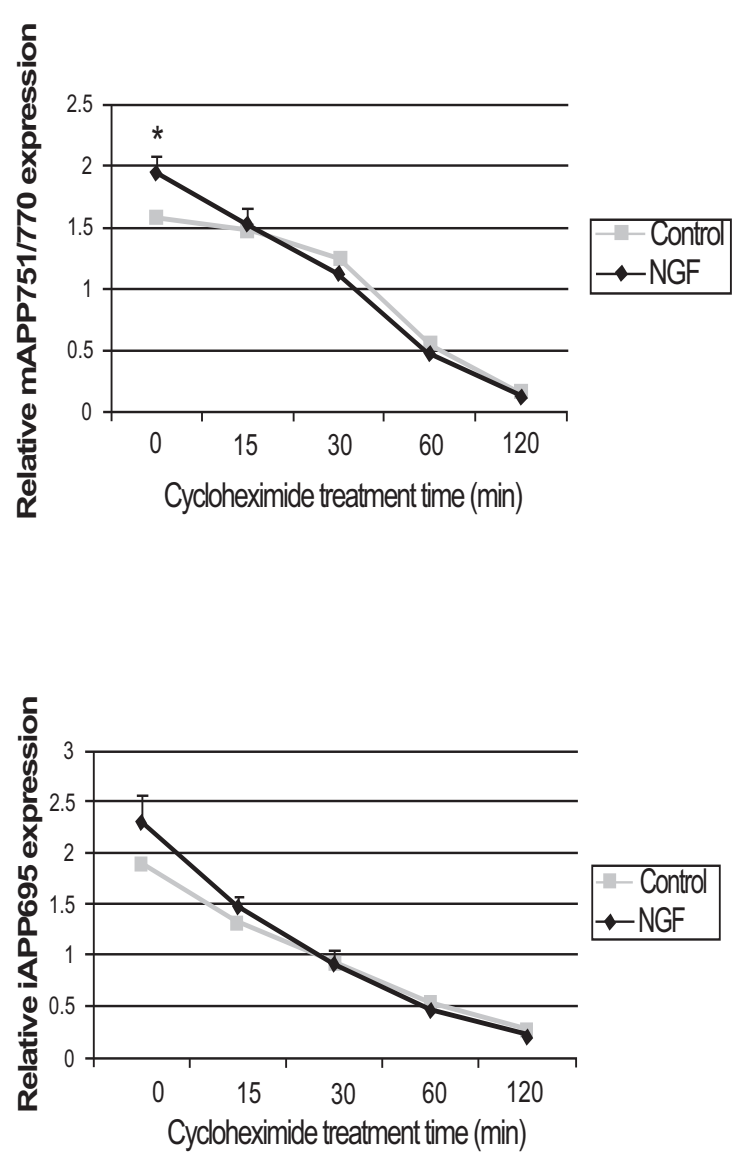

Fig. (2). APP protein levels in control and NGF-treated PC12 cells in the presence or absence of cycloheximide. (A) Representative immunoblots obtained from lysates of control (untreated) and NGF (50 ng/mL) treated PC12 cells treated with $10 \mu \mathrm{g} / \mathrm{mL}$ cycoheximide from $30 \mathrm{~min}$ to $2 \mathrm{~h}$. Samples were separated by SDS-PAGE and transferred to nitrocellulose membranes. The top panel represents total APP expression and the bottom panel shows the corresponding $\alpha$-tubulin levels in each sample. The top APP band represents mature (m) APP751/770, the middle APP band corresponds to immature (i) APP751/770 and mAPP695 and the lowest molecular weight APP band corresponds to iAPP695. Densitometric analysis of mature APP751/770 (B) immature APP751/770 and mature APP695 (C) and immature APP695 (D) protein levels normalized to $\alpha$-tubulin. Treatment with NGF for $72 \mathrm{~h}$ resulted in a statistically significant $(* \mathrm{p}<0.05)$ increase in mature APP751/770 and immature APP695 levels. Data are presented as the mean \pm SEM and represent 6 independent experiments. Statistical significance was determined by performing a one-way ANOVA followed by Tukey-Kramer’s multiple comparisons test to determine any significant differences between control and NGF treated samples at each time point. 


\section{Effect of L-NAME or S-MIU on APP mRNA Levels and Protein Stability}

Northern blot analysis was used to evaluate the effects of NOS inhibitors on APP mRNA levels. Densitometric analysis of mRNA levels for APP695 and APP751/770 normalized to $7 \mathrm{~s}$ following treatment with NGF and NOS inhibitors are depicted in Fig. (3). For both APP695 (Fig. 3A) and APP751/770 (Fig. 3B) there was a significant decrease in steady-state mRNA levels following treatment with 1.5 and $2.0 \mathrm{mM}$ S-MIU in comparison to control levels (*** p < 0.001). NGF also decreased the level of both transcripts but the levels of APP695 and APP751/770 mRNA were not different in samples obtained from NGF treated cells cultured with or without S-MIU. In contrast, treatment with L-NAME did not alter APP mRNA levels in either the presence or absence of NGF.

To determine whether NOS inhibition affected APP protein stability, control (untreated) and NGF-treated cells were grown in the presence or absence of $2.0 \mathrm{mM}$ S-MIU and treated with cycloheximide from $15 \mathrm{~min}$ to $2 \mathrm{~h}$. Densitometric analysis of APP isoform protein levels are presented in Fig. (4). There was no difference in the level of the highest molecular weight APP isoform in samples obtained from control or S-MIU-treated cells but a

A

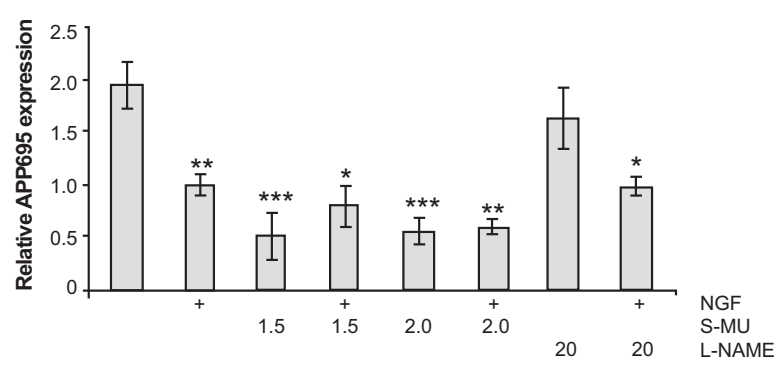

$\mathrm{B}$

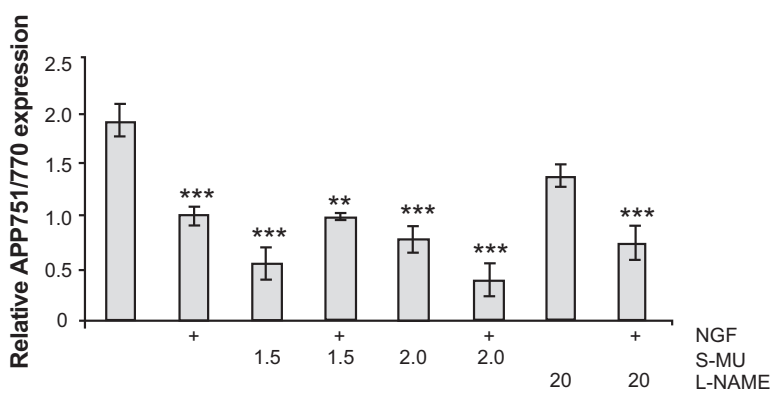

Fig. (3). Northern blot analysis of steady-state APP and 7s mRNA levels after treatment with increasing concentrations of S-MIU and 20mM L-NAME in the presence or absence of NGF. (A) APP695 mRNA levels: NGF (50 ng/mL) alone and 1.5 or $2.0 \mathrm{mM} \mathrm{S-MIU}$ with and without NGF significantly $(* \mathrm{p}<0.05$; ** $\mathrm{p}<0.01$; *** $\mathrm{p}$ $<0.001$ ) decreased APP695 mRNA levels as compared to control. (B) APP751/770 mRNA levels: NGF alone, and the two concentrations of S-MIU in the presence or absence of NGF significantly (** $\mathrm{p}<0.01$; ${ }^{* *} \mathrm{p}<0.001$ ) decrease in APP751/770 mRNA levels as compared to control. Data are presented as the mean \pm SEM and represent 6 independent experiments. Statistical significance was determined by a one-way ANOVA followed by the Dunnett test. statistically significant difference between the levels of this isoform in control and S-MIU treated cells following treatment with cycloheximide for 60 and $120 \mathrm{~min}$ was observed $\left({ }^{*} \mathrm{p}<0.05\right.$; Fig. 4A). The levels of immature APP751/770 isoform and mature APP695, which were quantified together (Fig. 4B) and immature APP695 isoform (Fig. 4C) were significantly lower in cells treated with SMIU as compared to control $\left({ }^{* *} \mathrm{p}<0.01\right)$. In the presence of cycloheximide, the level of these APP isoforms declined steadily, while in the presence of S-MIU and cycloheximide, the levels of APP protein remained constant resulting in significantly lower levels of the smaller isoforms of APP in control cells as compared to those treated with S-MIU following treatment with cycloheximide for 60 and $120 \mathrm{~min}$ $\left({ }^{*} \mathrm{p}<0.05 ;{ }^{* *} \mathrm{p}<0.01\right)$. In the presence of NGF, there was no difference in the levels or the rate of decay of mature APP751/770 in cells cultured with or without S-MIU (Fig. 4D). In cells treated with NGF and S-MIU, the relative level of the middle APP band, containing immature APP751/770 and mature APP695 (Fig. 4E) was significantly lower in NGF-treated cells pretreated with S-MIU prior to cycloheximide treatment $\left({ }^{*} \mathrm{p}<0.05\right)$ and significantly higher following $2 \mathrm{~h}$ of exposure to cycloheximide $\left({ }^{*} \mathrm{p}<0.05\right)$ when compared to cells treated with NGF alone. Densitometric analysis of the band containing the immature APP695 isoform (Fig. 4F) revealed a significantly lower level of this APP isoform in cells treated with NGF and S-MIU as compared to those treated with NGF alone $\left({ }^{* *} \mathrm{p}<0.01\right)$. In the presence of cycloheximide, immature APP695 levels in cell extracts of NGF-treated cells declined steadily over time, while in cells receiving both NGF and S-MIU, the level of this APP isoform remained constant resulting in significantly higher levels of immature APP695 in cells that received NGF and S-MIU compared to those exposed to NGF alone at the 120 min cycloheximide treatment time point $\left({ }^{* *} \mathrm{p}<0.01\right)$.

\section{DISCUSSION}

In PC12 cells, NGF treatment induces neurite outgrowth and increases the levels of APP protein [7, 10, 16 - 18], and we reported previously that NO modulates both of these actions of NGF [7]. To assess the mechanisms through which NO regulates these actions, we examined the effects of NGF, L-NAME and S-MIU on APP mRNA levels and protein stability. While NGF did increase APP protein levels, steadystate APP mRNA levels were decreased in NGF-treated PC12 cells. Although the estimated half-life of APP mRNA was lower in NGF-treated cells compared to control, this difference was not statistically significant. It was also demonstrated that the administration of NGF did not alter the stability of APP protein. These data suggest that, NGF may elevate APP levels in part through enhanced translation. A similar decrease in APP mRNA levels was observed in PC12 cells grown in the presence of the iNOS selective inhibitor, S-MIU. In contrast, L-NAME, the non-selective inhibitor, did not alter APP mRNA levels and neither inhibitor affected the ability of NGF to lower APP mRNA expression. In addition, treatment of PC12 cells with S-MIU resulted in a decrease in the level of APP protein, but an increase in APP half-life, primarily affecting the APP695 isoform. When NO production was inhibited, the basal levels of APP mRNA and protein were reduced and the increase in APP protein expres- 
sion normally observed following NGF treatment was prevented. However, in both control and NGF-treated cells, the protein half-life of APP was prolonged in the presence of SMIU, indicating NO plays a dual role in regulating APP levels.

Several APP isoforms can be produced from the APP gene however; APP695, APP751, and APP770 predominate in most mammalian tissues (reviewed in [19]). These isoforms can exist in both immature and mature forms, with mature forms being $\mathrm{N}$ - and O-glycosylated and tyrosyl sulfated as a result of post-translational processing [20]. APP695 is highly expressed in neurons [21] and it is the mature form of this isoform that is phosphorylated during PC12

A

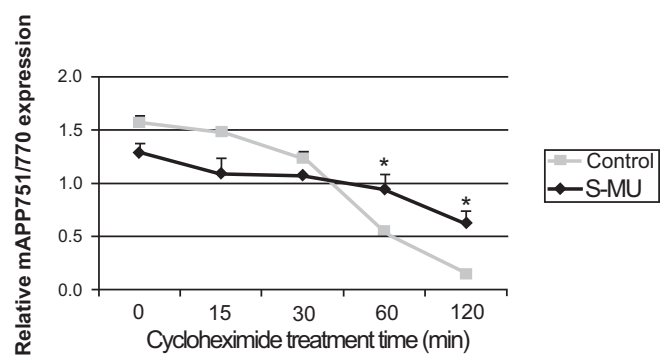

C

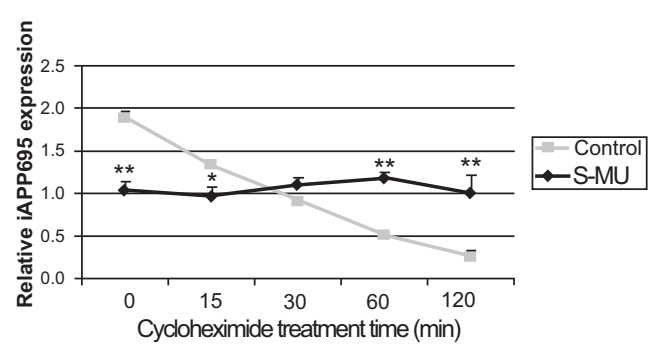

E

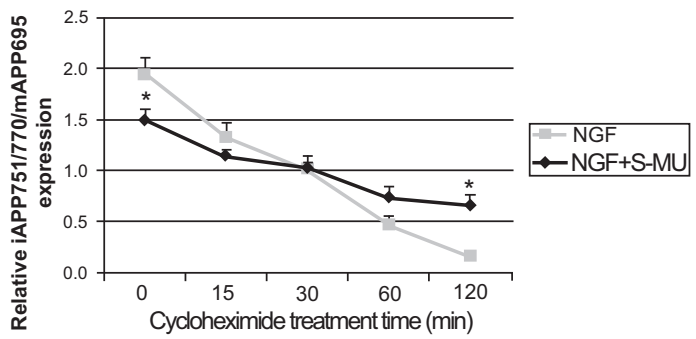

cell differentiation [16]. Our finding that NO plays a dual role in modulating the levels of the APP695 isoform could be important with respect to understanding the regulation of neuronal APP expression and the role of both NO and APP in neuron function and in regulating the outgrowth of neurites.

We and others have reported that NGF enhances the expression of both APP [7 - 10, 22 - 25] and NOS [11, 12, 26] and both NO [11, 12] and APP [16 - 18] have been identified as important contributors to neurite extension. While the interplay between NO and APP has not been fully elucidated, several studies have highlighted links between APP and NO. The c-terminal fragment of APP was reported to

B

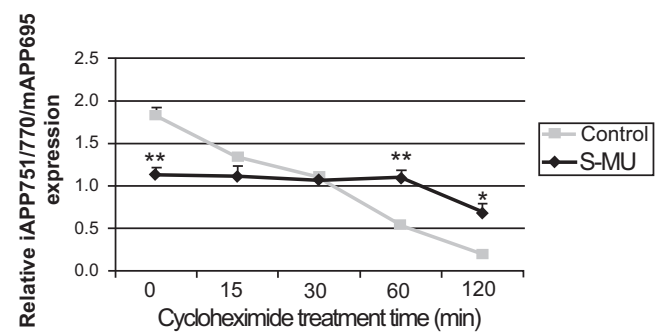

D

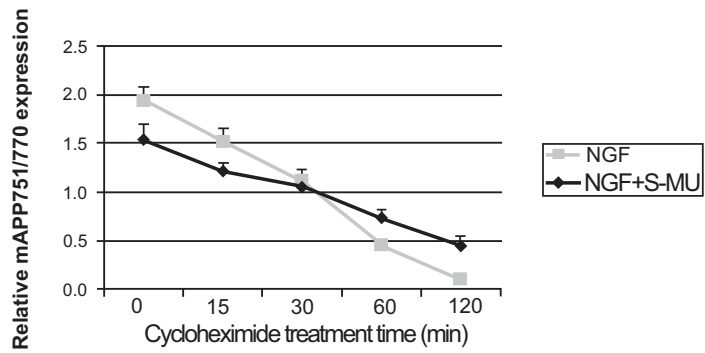

$\mathrm{F}$

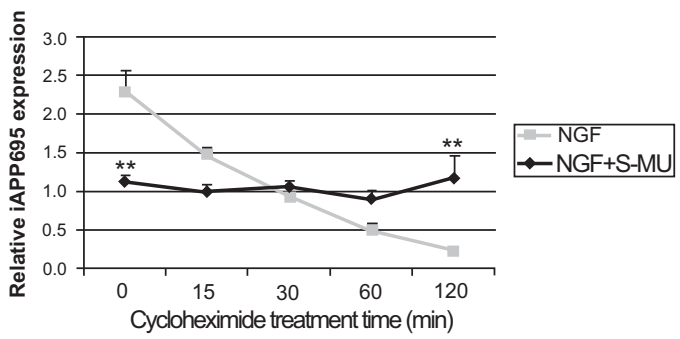

Fig. (4). APP protein levels following cycloheximide treatment in control and NGF-treated PC12 cells grown in the presence or absence of S-MIU. Densitometric analysis of mature (m) APP751/770 (A) immature (i) APP751/770 and mAPP695 (B) and iAPP695 (C) protein expression normalized to $\alpha$-tubulin in untreated (control) and $2.0 \mathrm{mM}$ S-MIU-treated PC12 cells. No difference in relative mAPP751/770 levels was observed between control cells and those grown in the presence of S-MIU but the level of this isoform was significantly higher in cells grown in the presence of S-MIU following treatment with cycloheximide for 60 and 120 min $\left({ }^{*} \mathrm{p}<0.05\right)$. Relative densities of the bands containing APP695 in S-MIU treated PC12 cells were significantly different from control in the absence of cycloheximide $(* * \mathrm{p}<0.01)$ and following 60 and 120 mins of treatment with cycloheximide $\left({ }^{*} \mathrm{p}<0.05\right.$; $\left.{ }^{* *} \mathrm{p}<0.01\right)$. Densitometric analysis of mAPP751/770 (D) iAPP751/770 and mAPP695 (E) and iAPP695 (F) protein expression normalized to $\alpha$-tubulin samples obtained from 50 ng/mL NGF-treated PC12 cells grown in the presence or absence of $2.0 \mathrm{mM}$ S-MIU. The relative density of bands containing the APP695 isoform was significantly different in cells treated with NGF alone compared to cells treated with NGF in the presence of S-MIU in the absence of cycloheximide $\left({ }^{*} \mathrm{p}<0.05 ;{ }^{* *} \mathrm{p}<0.01\right)$ and following 120 mins of treatment with cycloheximide $\left({ }^{*} \mathrm{p}<0.05 ; * * \mathrm{p}<0.01\right)$. Data are presented as the mean \pm SEM and represent 5 independent experiments. Statistical significance was determined by performing a one-way ANOVA followed by Tukey-Kramer's multiple comparisons test to determine any significant differences between NGF treated samples grown in the presence or absences of S-MIU at each time point. 
increase iNOS expression and NO production $[27,28]$ and both APP and constitutive NOS were found to be elevated in a subset of neurons following injury [29]. We reported previously that treatment with NOS inhibitors attenuated NGFstimulated APP promoter activation and the increase in protein levels [7]. To further characterize the link between NO and APP, the actions of NGF and NOS inhibitors on APP mRNA levels and APP protein stability were evaluated.

Previous studies reported that NGF induction of APP mRNA involves activation of the Ras-MAPK signalling pathway [22, 25]. We and others have shown that NO modulates the MAPK signalling pathway $[30,31]$ suggesting NO could also play a role in the regulation of APP mRNA expression. In contrast to previous reports, using both real-time PCR and northern blot analysis, we found that treatment of PC12 cells with NGF decreased steady-state APP mRNA levels. It is possible that different cell types or lines of PC12 cells exhibit different gene expression profiles. The PC12 cells used in the present study were from American Type Culture Collection (ATCC, Rockville, MD, USA) while other studies investigating APP mRNA levels used primary neurons [9] or PC12 cells supplied by Dr. L. Greene [10]. The decrease in APP mRNA levels observed in the present study was not isoform specific as the steady-state mRNA levels of both APP695 and APP751/770 were below control values following treatment with NGF. The observed decrease in APP mRNA levels was surprising as it did not correlate our previous NGF-induced transcription and protein expression findings [7]. Using the same cell line and treatment conditions, we reported previously that APP promoter activity was increased following treatment with NGF and that the NGF-induced increase in APP protein levels was attenuated by pre-treatment with the transcription inhibitor actinomycin D [7].Our initial findings agreed with previous reports [8-10] and indicated that the NGF-mediated increase in APP protein levels was due to increased APP transcription however, the data in the present study suggest that this enhanced transcription does not result in increased APP mRNA levels. Taken together, these findings suggest the enhanced transcription of APP induced by NGF is followed by rapid translation and degradation of APP mRNA. This rapid degradation of APP mRNA is supported by the lower estimated half-life observed in NGF-treated PC12 cells relative to control, however this difference was not statistically significant at the NGF treatment timepoint examined. Interestingly the iNOS selective inhibitor S-MIU also reduced APP mRNA expression and like NGF, the effect of S-MIU on APP mRNA levels was not isoform specific. We reported previously that S-MIU did not affect basal APP promoter activity [7] suggesting that this reduction in APP mRNA levels is also due to an alteration in mRNA stability and not the result of inhibiting APP transcription. Furthermore, while the levels of both APP695 and APP751/770 mRNA were reduced significantly in samples obtained from cells receiving both NGF and S-MIU relative to untreated (control) cells, these levels were not different from those measured in extracts obtained from cells receiving either of these treatments alone. This indicates that the effects of NGF and NOS inhibition on steady-state APP mRNA levels are not additive and could involve similar mechanisms. The finding in this study that APP mRNA expression is decreased in PC12 cells treated with NGF or NOS inhibitors is unique and requires further investigation.

To better understand how NGF and NO were affecting APP protein turnover, the effect of cycloheximide on untreated PC12 cells and cells treated with NGF or S-MIU alone and in combination was evaluated. We reported previously that the level of the APP695 isoform was increased significantly following $96 \mathrm{~h}$ of treatment with NGF. To determine whether this increase is due in part to alterations in protein stability, cycloheximide was added to PC12 cells 72 $\mathrm{h}$ after NGF treatment was initiated, the time at which the trend towards increased APP levels was first observed [7]. In the present study no change in the half-life of any of the APP isoforms was observed following exposure to NGF. Since NGF did not increase the levels of APP mRNA or protein stability, our findings suggest that in PC12 cells NGF increases APP protein expression through enhanced transcription, followed by rapid translation and degradation of APP mRNA. In contrast to NGF, the iNOS-selective inhibitor SMIU decreased the relative levels of APP protein in both the presence and absence of NGF but the degradation of APP was inhibited. These findings suggest that in addition to its role in regulating APP transcription NO could modulate mRNA stability as well as APP processing. NO was reported to increase the activity of tumor necrosis factor $\alpha$-converting enzyme (TACE) [32] and under conditions of ischemia, activation of NOS was found to increase beta-site APP cleavage enzyme 1 (BACE-1) expression [33]. If in our system NO causes a similar increase the activity or expression of TACE, BACE- 1 or one of the other $\alpha$-secretase candidates, this could affect the level of full-length APP protein detected. Similarly, inhibition of NOS could prevent the degradation of APP by secretases, resulting in the prolonged half-life of this protein. In the present study, treatment of PC12 cells with S-MIU resulted in a reduction in the relative levels of APP protein and enhanced the protein stability and these effects were most consistently observed for the APP695 isform. We therefore speculate that NO does indeed modulate both the expression and cleavage of neuronal APP. Future studies are necessary in order to explore this relatively uncharacterized role of NO.

Since APP plays an important role in neuron function and its cleavage products are involved in the pathogenesis of $\mathrm{AD}$, a better understanding of the mechanisms involved in regulating APP expression and its post-translational processing are necessary. The present study demonstrates that the NGFmediated increase in APP protein levels is not due to enhanced mRNA or protein stability and that NO, which is necessary for NGF-induced neurite outgrowth and increased APP protein levels in PC12 cells, modulates APP mRNA levels and protein stability. NO plays an important role in the regulation of APP expression and the neurotrophic actions of NGF. Additional studies on the mechanisms involved in these complex processes would provide valuable insight into the neuromodulatory actions of both NO and APP.

\section{ABBREVIATIONS}

$\begin{array}{ll}\mathrm{AD} & =\text { Alzheimer's disease } \\ \mathrm{A} \beta & =\text { Amyloid } \beta \text {-protein }\end{array}$




$\begin{array}{ll}\text { ANOVA } & =\text { Analysis of variance } \\ \text { APP } & =\text { Amyloid precursor protein } \\ \text { BACE-1 } & \text { Beta-site APP cleavage enzyme } 1 \\ \text { DMEM } & =\text { Dulbecco's modified Eagle medium } \\ \text { ECL } & =N^{\omega} \text {-nitro-L-arginine methyl ester } \\ \text { L-NAME } & \text { Nerve growth factor } \\ \text { NGF } & =\text { Nitric oxide } \\ \text { NO } & =\text { Nitric oxide synthase } \\ \text { NOS } & =\text { Phosphate buffered saline } \\ \text { PBS } & =\text { Sodium dodecyl sulfate } \\ \text { RIPA } & =\text { Standard error of the mean } \\ \text { SDS } & =\text { S-methylisothiourea } \\ \text { SEM } & \text { Tumor necrosis factor } \alpha \text {-converting en- } \\ \text { S-MIU } & \text { TRIS buffered saline } \\ \text { TACE } & \text { TBS containing } 0.1 \% \text { tween } 20 . \\ \text { TBS } & =\text { TBS-T }\end{array}$

\section{CONFLICT OF INTEREST}

None declared.

\section{ACKNOWLEDGEMENTS}

This research was funded by a discovery grant from the Natural Sciences and Engineering Research Council of Canada.

\section{REFERENCES}

[1] Walsh, D.M.; Selkoe, D.J. A beta oligomers - a decade of discovery. J. Neurochem., 2007, 101, 1172-1184.

[2] Selkoe, D.J. Normal and abnormal biology of the beta-amyloid precursor protein. Ann. Rev. Neurosci., 1994, 17, 489-517.

[3] Neve, R.L.; Finch, E.A.; Dawes, L.R. Expression of the Alzheimer amyloid precursor gene transcripts in the human brain. Neuron, 1988, 1, 669-677.

[4] Tanaka, S.; Shiojiri, S.; Takahashi, Y.; Kitaguchi, N.; Ito, H.; Kameyama, M.; Kimura, J.; Nakamura, S.; Ueda, K. Tissuespecific expression of three types of beta-protein precursor mRNA: enhancement of protease inhibitor-harboring types in Alzheimer's disease brain. Biochem. Biophys. Res. Commun., 1989, 165,14061414.

[5] Tanzi, R.E.; McClatchey, A.I.; Lampert, E.D.; Villa-Komaroff, L.; Gusella, J.F.; Neve, R.L. Protease inhibitor domain encoded by an amyloid protein precursor mRNA associated with Alzheimer's disease. Nature, 1988, 331, 528-530.

[6] Seiger, A.; Nordberg, A.; von Holst, H.; Backman, L.; Ebendal, T.; Alafuzoff, I.; Amberla, K.; Hartvig, P.; Herliltz, A.; Lilja, A.; Lundqvist, H.; Långström, B.; Meyerson, B.; Persson, A.; Viitanen, M.; Winblad, B.; Olson, L. Intracranial infusion of purified nerve growth factor to an Alzheimer patient:the first attempt of a possible future treatment strategy. Behav. Brain. Res., 1993, 57,255-261.

[7] Binnington, J.C.; Kalisch, B.E. Nitric oxide synthase inhibitors modulate nerve growth factor-mediated regulation of amyloid precursor protein expression in PC12 cells. J. Neurochem., 2007, 101, 422-433.

[8] Fukuyama, R.; Chandrasekaran, K.; Rapoport, S.I. Nerve growth factor -induced neuronal differentiation is accompanied by differential induction and localization of the amyloid precursor protein
(APP) in PC12-cells and variant PC12S-cells. Mol. Brain Res., 1993, 17, 17-22.

[9] Ohyagi, Y.; Tabira, T. Effects of growth factors and cytokines on expression of amyloid beta protein precursor messenger RNAs in culture neuronal cells. Mol. Brain Res., 1993, 18, 127-132.

[10] Roßner, S.; Ueberham, U.; Schliebs, R.; Perez-Polo, J.R.; Bigl V. p75 and TrkA receptor signaling independently regulate APP mRNA expression, isoform composition and protein secretion in PC-12 cells. J. Neurochem., 1998, 71, 757-564.

[11] Kalisch, B.E.; Bock, N.A.; Davis, W.; Rylett, R.J. Inhibitors of nitric oxide synthase attenuate nerve growth factor-mediated increases in choline acetyltransferase gene expression in PC12 cells. J. Neurochem., 2002, 81, 624-635.

[12] Peunova, N.; Enikolopov, G. Nitric oxide triggers a switch to growth arrest during differentiation of neuronal cells. Nature, 1995, 375, 68-73.

[13] Southan, G.J.; Szabo, C.; Thiermermann, C. Isothioureas: potent inhibitors of nitric oxide synthases with variable isoform selectivity. Br. J. Pharmacol., 1995, 114, 510-516.

[14] Bradford, M. A rapid and sensitive method for the quantitation of microgram quantities of protein utilizing the principle of proteindye binding. Anal. Biochem., 1976, 72, 248-254.

[15] Allan, A.L.; Albanese, C.; Pestell, R.G.; LaMarre, J. Activating transcription factor 3 induces DNA synthesis and expression of cyclin D1 in hepatocytes. J. Biol. Chem., 2001, 276, 27272-27280.

[16] Ando M.; Oishi, M.; Takeda, S.; Iijima,K.; Isohara, T.; Nairn, A.C.; Kirino, Y.; Greengard, P.; Suzuki, T. Role of phosphorylation of Alzheimer's amyloid precursor protein during neuronal differentiation. J. Neurosci., 1999, 19, 4421-4427.

[17] Luo, J.; Wallace, M.S.; Hawver, D.B.; Kusiak, J.W.; Wallace, W.C. Characterization of the neurotrophic interaction between nerve growth factor and secreted $\alpha$-amyloid precursor protein. $J$. Neurosci. Res., 2001, 63, 410-420.

[18] Milward, E.A.; Papadopoulos, R.; Fuller, S.J.; Moir, R.D.; Small, D.; Beyreuther, K.; Masters, C.L. The amyloid protein precursor of Alzheimer's disease is a mediator of the effects of nerve growth factor on neurite outgrowth. Neuron, 1992, 9, 129-137.

[19] Jacobsen, K.T.; Iverfeldt, K. Amyloid precursor protein and its homologues: a family of proteolysis-dependent receptors. Cell Mol. Life Sci., 2009, 66, 2299-2318.

[20] Da Cruz e Silva, E.H.; daCruz e Silva, O.A. Protein phosphorylation and APP metabolism. Neurochem. Res., 2003, 28, 1553-1561.

[21] Kang, J.; Müller-Hill, B. Differential splicing of Alzheimer's disease amyloid A4 precursor RNA in rat tissues: PreA4(695) mRNA is predominantly produced in rat and human brain. Biochem. Biophys. Res. Commun., 1990, 14, 1192-1200.

[22] Cosgaya, J.M.; Latasa, M.J.; Pascual, A. Nerve growth factor and ras regulate beta-amyloid precursor protein gene expression in PC12 cells. J. Neurochem., 1996, 67, 98-104.

[23] Ge, Y.W.; Lahiri, D.K. Regulation of promoter activity of the APP gene by cytokines and growth factors:implications in Alzheimer's disease. Ann NY Acad. Sci., 2002, 973, 463-467.

[24] Higgins, G.A.; Oyler, G.A.; Neve, R.L.; Chen, K.S.; Gage, F. Altered levels of amyloid protein precursor transcripts in the basal forebrain of behaviourally impaired aged rats. Proc. Natl. Acad. Sci. USA., 1990, 87, 3032-3036.

[25] Villa, A.; Latasa, M.J.; Pascual, A. Nerve growth factor modulates the expression and secretion of beta-amyloid precursor protein through different mechanisms in PC12 cells. J. Neurochem., 2001, 77, 1077-1084.

[26] Sheehy, A.M.; Phung, Y.T.; Reimer, R.K.; Black, S. Growth factor induction of nitric oxide synthases in rat pheochromocytoma cells. Mol. Brain Res., 1997, 52, 71-77.

[27] Bach, J.H.; Chae, H.S.; Rah, J.C.; Lee, M.W.; Park, C.H.; Choi, S.H.; Choi, J.K.; Lee, S.H.; Kim, Y.S.; Kim, K.Y.; Lee, W.B.; Suh, Y.H.; Kim, S.S. C-terminal fragment of amyloid precursor protein induces astrocytosis. J. Neurochem., 2001, 78, 109-120.

[28] Rah, J.C.; Kim, H.S.; Kim, S.S.; Bach, J.H.; Kim, Y.S.; Park, C.H.; Seo, J.H.; Jeong, S.J.; Suh, Y.H. Effects of carboxyterminal fragment of Alzheimer's amyloid precursor protein and amyloid betapeptide on the production of cytokines and nitric oxide in glial cells. FASEB J., 2001, 15, 1463-1465.

[29] Lüth, H.; Arendt, T. Co-expression of APP with cNOS but not iNOS after cortical injury in rat. Neuroreport, 1997, 8, 2321-2324.

[30] Kalisch, B.E.; Demeris, C.S.; Rylett, R.J. Modulation of nerve growth factor-induced activation of MAP kinase in PC12 cells by 
inhibitors of nitric oxide synthase. J. Neurochem., 2003, 87, 13211332.

[31] Kanterwicz, B.I.; Knapp, L.T.; Klann, E. Stimulation of p42 and p44 mitogen-activated protein kinases by reactive oxygen species and nitric oxide in hippocampus. J. Neurochem., 1998, 70, 10001016.

[32] Zhang, A.; Kols, J.K.; Oliver, P.; Good, D.; Schwarzenberger, P.O.; Hoshi, M.S.; Ponthier, J.L.; Lancaster, J.R. Jr. Activation of tumor necrosis factor- $\alpha$-converting enzyme-mediated ectodomain shedding by nitric oxide. J. Biol. Chem., 2000, 275, 15839-15844.

[33] Li, S.; Wang, W.; Wang, C.; Tang, Y.Y. Possible involvement of $\mathrm{NO} / \mathrm{NOS}$ signaling in hippocampal amyloid-beta production induced by transient focal cerebral ischemia in aged rats. Neurosci. Lett. 2010, 470, 106-110.

Received: September 19, 2011

(c) MacKinnon et al.; Licensee Bentham Open.

This is an open access article licensed under the terms of the Creative Commons Attribution Non-Commercial License (http://creativecommons.org/licenses/by-nc/3.0/) which permits unrestricted, non-commercial use, distribution and reproduction in any medium, provided the work is properly cited. 